\title{
Improvement of cognitive ability of English language learners through writing skills.
}

\author{
Saddam H.M. Issa* and Shyamala K.C ** \\ * Research Scholar, Department of Linguistics, University of Mysore, India \\ ** Prof in language pathology (Retd), AIISH, Mysore
}

ABSTRACT- This paper explores the interrelation between the cognitive linguistic skills that are necessary for children to write on both words and texts. Three types of cognitive-linguistic abilities, which were considered to be more specifically interested in the text writing research, were transcriptional skills, ideation and syntax. The first two emerged out of a simplistic writing view (Berninger, 2010) while the predicted value of syntactic skills was based on an "extended triangle model" (Bishop \& Snowling, 2011). The transcription skills in the present research have been operationalized to generate strokes in line with the proper order of stroke. With respect to the ideation, we tested the capacity of children to create orally sentences on such subjects and the requirements for grading are close to the criteria of text composition. Although good handwriting enhances student reading, improves skills, the process of abandoning handwriting has already started in a number of countries. This study paper reveals that handwriting is not only meant for primary school students, but also in high school education with regard to some important studies.

Keywords: Handwriting, Cognitive, Transcriptional Skills, Ideation, Syntax Article Received: 10 August 2020, Revised: 25 October 2020, Accepted: 18 November 2020

\section{INTRODUCTION}

Language learning is not a single cognitive process act but the capacity of an individual to consider, interpret, think, judge and be mindful. There are numerous ways of visual representation. This is considered one of the most characteristic skills of human language learning. Language skills are an asset for successful communication. Human aim, as the divine virtues of creation, immortality, unity, strength, honesty, beauty, compassion, compassion and goodness have been assimilated. Many of these are only understood through intelligence (R.S. Naagarazan, 2006).

Each human being can only intuit (understand or function by instinct) his own mind's nature, and no one has clear access to another's intelligence. It means that only students can support themselves. Learning is the practice of developing new ideas, behaviors, abilities, beliefs and desires and changing them. Language development is the mentally complex cognitive features that includes high motivation and self-awareness. The ability to read, grasp and understand concepts, prepare, solve challenges and use language to communicate. The language enhances human potential. Language is brain capability, analytical abilities, thinking powers, thinking powers and thought powers to allocate mental disorders.

The neural networks between the linguistic areas of the brain and the neural networks between language theory areas of the brain are closely related. Human learning began before birth and lasts before death due to the continuing connections between physical world and the human mind impressively interacts with the brain. Neurotransmitters such as dopamine regulate human speech mechanism have been investigated. Why dopamine can be successful and fun in learning a foreign language. The essence and processes involved in schooling, including pedagogy and teaching methods, are researched in many areas. Youth colleges and schools should have the learning phases and language components, then 
teach English. This will help college students understand that studying is a luxury for explorers and it is fascinating to know how people learn, how fun, enthusiasm, aspiration, creativity, selfdiscipline, competition, teamwork, etc can emerge. Cognitive functions contribute to awareness, with both information acquisition processes and means. Encompassing reading contributes directly to the processing of knowledge and thus to the maintenance of know-how.

Writing is one of those skills which in second language learning are considered very necessary. Writing cannot be obtained naturally; rather it is taught through systematic teaching. In writing, it is common for students to make mistakes. As Brown (2007) argues, "learners inevitably make mistakes in the acquisition process and this process is impeded if they make no mistake and then benefit from diverse feedbacks on these mistakes." Ferris (2010) suggests that further research could explore the position of contextual and individual differences between learners. She claims that a significant gap in WCF research has been due to the absence of adequate research on these aspects. There are several variables that can affect the perceptions of students such as age, sex, ability level, motivation and way of thinking.

Cognitive factors among these individual factors seem to play an important part in the effectiveness of feedback and written growth (Rahimi, 2015). One of the cognitive variables left unexplored is the cognitive styles of teachers that are considered potentially important in second language learning. A successful written assessments creativity includes a combination of what is learned from both a cognitive and an instructional point of view of writing to assess writing in ways that are helpful to teachers, students and policymakers, without the underlying process being aggressive. Historically, the teaching of academic writing is focused on so-called forms (for example, expository, descriptive, narrative, argumentative and persuasive) and in particular, on writing and argumentation of exposition. In this connection, writing can be seen as a specific form of capacity for verbal development in which text is generated to fulfil the demand for a discourse or more generally, as a dynamic and interconnected output that cannot be understood except for the social and cognitive purposes it serves.

In a social environment, people write to achieve communicative goals, and so is writing in a school sense. For different purposes, successful training provides students with the skills they need to produce a wide variety of texts in a wide range of social contexts. This analysis would take a wider perspective and as such, we define professional writing as a dynamic cognitive task that requires problem solving and strategies to meet communicative objectives.

In order to facilitate dynamic knowledge exchange, exposure presupposes all the abilities incorporated in narrative texts and adds various techniques. Usually, persuasive writing combines narrative and expository elements, incorporating persuasion and argument as required. Therefore an implied hierarchy of skills can be drawn up in prose, which ranges widely in cognitive sophistication, from basic narratives to nuanced arguments and literary skills. The conventional methods of writing are purely academic, as skilled authors may compose texts that incorporate elements of all traditional methods in order to achieve their immediate rhetorical objectives (cf. Rowe, 2008, p. 407). Conventional modes, however are of interest because they reflect genuine differences in the underlying skills needed to succeed as a writer.

A long-term Cognitive Based Assessment for and as a Learning Initiative (CBAL) is currently being undertaken by ETS to create a cognitive- 
based assessment framework centered on K-12 education. These evaluations will incorporate and connect accountability assessments with formative classroom assessments; accountability and formative assessments are designed to work together effectively to improve learning. This study describes the nature of the writing abilities addressed in cognitive literature with the immediate purpose of defining the components of an expertise model.

Language development is intellectually complex cognitive accomplishments that involve a high degree of motivation and self-awareness. Students from colleges who may feel abandoned have many reasons, but the deficiency in the English language is clearly a recurring problem. In this paper we address the influential assets of enriching English language outlets and how they can be constructed to inspire international students' opportunities. The paper will explain how the mind works as an adversary for those young people who cannot control it. The power of the language is not due to its physical skill, but rather to its unbearable willingness.

\section{Cognitive Models of Writing}

In terms of solving issues, cognitive models tend to explain writing (cf. McCutchen, Teske, \& Bankston, 2008). In fiction, the attempt of the writer to map language into his own thoughts and feelings, as well as the impressions of the reader, generally poses problems. The difficulty of writing is shown by this initiative, as problems can vary from strategic aspects (such as organizing ideas) for the execution of plans A skilled writer will face an enormous hierarchy of problems, including how task-specific concepts are constructed and organized; word flowing phrases are grammatically correct; punctuation and spelling are correct; and customize ideas, tones and text to name some of the most outstanding rhetorical and linguistic tasks for the desired audience. Obviously, skillful writing would require a sophisticated approach to problems. It is suggested that qualified writers sometimes "disturb" a writing assignment, following a technique called transforming information.

Expert writers also develop elaborate objectives, particularly content and rhetorical objectives that involve complex problem solving. In comparison, inexperienced writers typically take a simpler, more natural approach to writing by pursuing a knowledge approach that incorporates material and one notion. Although the inefficient abilities of novices can restrict them to an information, skilled writers can freely switch between information reporting and knowledge transformation. In terms of information processing, problem solving has been conceptualized. It sought to define various activities while writing and their relationships with the working environment and the internal knowledge of the author in its original model, which was widely accepted in the area of writing science. Hayes and Flower suggested that the writer's long-term memory has different kinds of content, including the subject, audience awareness and written plans. The written assignment (including topics, audiences and motivational elements) was differentiated by Hayes and Flower from the previously created text.

\section{Writing as Cognition: psychological Perspective}

The literature researcher reviewed so far focused on writing purely from a cognitive psychological viewpoint, focusing exclusively on what happens in the author's mind. Another view of writing takes account of the cognitive essence of writers abilities are socially positioned and exist in social environments, promoting and encouraging specific ways of thought. Sociocultural writing 
methods stress that writing is a) situated in real uses; (b) improvised, not solely in accordance with abstract templates; (c) mediated by social practices and conventions; and (d) learned as part of socialization of specific practices.

The sociocultural approach stresses that the actual traditions of the group have an important effect on what styles of writing activities are to be carried out the way they are organized and how they are received and that such structures as genre or writing methods are simply traditional structures that arise in particular social contexts and are incorporated into a customs and standards dynamic. The literary practices differ among classes in the same society and that cultural practices at home and in the community can increase or conflict with school-built literacy and standards. Different sociocultural studies have shown that genres are usually formed in ways that indicate particular changes in the structure and practise of groups. There was a mistake (Bazerman, 88; Bazerman, \& Prior, 2005). In short, the purposes for which writing is used the social norms governing those ends, the writers' unique forms of expression, writing instruments and other cultural activities, all of which are a wider social context that informs, promotes and ultimately constitutes a writer's work. Writing skills remain within the social space of these environments and their respective organizations and activities.

Naturally, the type of writing we deal with in this study is school writing: a type of writing socially advantageous in the academic sense, and that is an important tool to success in many contexts including the wide-ranging academic and commercial life of Western society in the 21st century. We do not have any specific apology for this restriction, as it is explicitly motivated by our overall goal - to encourage more successful written evaluation and instruction in a school setting - but it is necessary to note this reach limitation.
Many of the cognitive requests of this form of writing are motivated by the requirement of a culture of literary debate, in which interactions are asynchronous; mediated by publication or other impersonal communication methods, and often involves the communication of material and ideas when the assumption of knowledge, involvement, participation or sharing is not secure.

The transitional students as new university students as they had to learn how to compose texts effectively according to university social norms. Researcher discussed how the demands of that social context questioned students' habits and perceptions in a view of secondary school. The social practices and related information necessary to carry out the kinds of research required to write well in social contexts where rival theories need to be produced, considered and evaluated. While much of the remainder of this analysis focuses on a reasonably detailed examination of certain cognitive abilities and abilities required for the successful performance of characteristic styles of academic writing, it is important to bear in mind that all of these occur as practice within a specific context and cultural context. It is important to bear in mind that cultural cultures provide the ultimate measure of writer effectiveness to the degree that both writer instructions and written evaluations are cultural practices themselves, and are part of the same context. The evaluation should reflect on whether students have the knowledge and skills to take full part in the group dialogue and practice their writings.

The several distinct cognitive processes involved in writing should in particular be taken into consideration without losing sight of the fact that they are part of a larger social situation. It can be complex by involving both readers and other social actors, such as reviewers, editors and so on and a rich social context in which contemporary 
writing and a wide variety of social institutions are involved. The tension between the need to measure foreign writing (awareness of a social context and a rhetorical objective) and the need to quantify those skills and competencies which are part of expert writing is one of the resulting conflicts addressed in the final sections of this paper.

Effects on verbal, psychological and didactic elements of writing processes were summarized. He also challenged high school pupils to do difficult writing activities - adding paraphrases to a scientific text or writing an argumentative text based on a concrete argument. He demonstrated how writing research opened new insights for writing didactics. Several academic articles on writing didactics have called attention to the psycholinguistic research into writing processes. The paper, which has been written together by a language psychologist and a didactic expert, provides a problemmatization of the potential fields of collaboration between the two disciplines, each demonstrating the interests of their relationship with the unique and complementary duties of both disciplines.

In this paper we suggest that the advancement of both psychological understanding and instructional experience is a cognitive approach to writing. The shortcomings of these analyses and their teaching consequences are known to it: "psychologists conclude that the recent research of writing processes have led only to very ingenuous descriptive attempts and very restricted theory."

\section{Review of literature}

In Britain, 11 years of age is one fifth of our high school leavers, while another five million adults have "under-functional" literacy skills (Sippett, 2015). It translates into 1 in 7 employees.
Similarly, a government survey in 2012 said that nearly 20 percent of just over 650,000 high school leavers were "functionally analphabets". This implies that nothing more than basic questions about a given text can be dealt with. (Shepherd, 2010). In other words, at the bottom of the Bloom taxonomy they cannot decipher interrogations (who, what, where, where, etc.) but not higher imperatives (such as clarification, analysis, implementation, evaluations, etc.) requiring a more comprehensive collection of reading skills. In addition, it is highly questionable (and 'impossible'), according to the UK Guardians, that many will remember such GCSE characteristics as allusion and irony ('Shepherd, 2010'). This disease has clearly raised the eye of policymakers (Morgan, 2016).

There is concern, for example, that a large number of British citizens do not achieve the requisite skills to be effective in education, work or their personal lives (Feder \& Majnemer, 2007; Graham \& Perin, 2007). However this particular study does not show that the connection between literacy (the ability to read and understand a text) and writing is established (the ability to convey clarity and structure of thoughts and ideas). The two distinct elements are taught in relation to each other more often than not, as the subject of English (such as delivery and assessment) does not clearly distinguish between these two entities. One common reason why young people may not write well is that schools may not take the nuances of writing skills into account or have adequate policies, resources or investments that can contribute to the teaching of these skills.

Many schools do not completely understand the processes involved in acquiring skills for readable handwriting nor relate to success and achievement. However there are many layers of complexity and the handwriting orthography abilities. The integration of the orthographic motor 
is the ability to remember and write letter forms, letter groups and words without giving cognitive attention. There are items that universities overlook. Simplified handwriting involves the regulation and alignment of muscles and the fingertips, of the hand and of the arm, and simultaneous bending or stretching of the thumb and finger of the hand, as well as the removal and holding of the hand around the wrist joint. Some studies show that learning is eventually connected to writing (Graham \& Perin, 2007). These results point to an ontological distinction between 'learning to write' and 'learning to write.'

The former concerns reading and the ability to write, while the latter concerns the accuracy and speed of writing, with pen and paper letters and phrases. There are two distinct principles of pedagogy which exist. While the learning handwriting process is carried out at primary school level with some enthusiasm, it soon disappears or is forced to side with it when students go to secondary school. (Medwell \& Wray, 2008). This is because it is believed that students have mastered handwriting only after primary school, because they can write and thus do not need any further education in this field. Although literacy and English language have regained prominence in grammar (referred to by OFSTED and examination boards such as AQA and the White Paper Directives, the Value of Teaching, 2010 (which was the cornerstone of the Education Act of 2011), there is very little focus on handwriting abilities for teenagers (Medwell \& Wray, 2008). However, studies in the USA and the UK have shown the value of handwriting (in particular, different types of cursive writing) in improving the cognitive skills of students. Good handwriting skills can help pupils to achieve academic success particularly with regard to orthography and vocabulary (Cripps \& Cox, 2008). Studies have identified such associations with pupils' writing quality and mental ability to process and obtain knowledge.

While very little research specifically suggests that handwriting creates academically talented pupils, the potential for pupils to do well is increased as a direct result of their handwriting. The learning of strong handwriting skills helps with the language and visual regularity of the pupils. For example, in some areas of education psychology it is claimed that good cursive writing helps pupils to relate to their language work. In particular, it improves the automaticity of pupils. The term automatism refers to the ability of students to reproduce correct word types with letters, loops and joints without constantly recalling and checking their accuracy (Feder \& Majnemer, 2007). The automaticity is contingent upon the efficiency of students to bring the language to the page from the brain. It is however different from the orthographic integration, as the latter relies on dexterity and/or manipulation of the hand and wrist.

In exchange, these skills combined are likely to increase the pace at which students write (Peverley, 2006) and schoolchildren are bound by the incorporation of equal opportunity and diversity, safeguarding and citizenship. These elements are critical at the moment, as is the confidence of students in their use of language and emotional selves in the national curriculum highlighted by government and policymakers in the form of laws and directives. Written teaching skills should concentrate on particular students (such as their learning needs, their weaknesses etc.).

The quality of student handwriting demonstrates not only facets of hand/eye coordination, but also other issues such as dyslexia and ADH (USA Department of Education, 2004). It advises reexamining our handwriting attitudes by analyzing the present situation and the historical context in which handwriting has played a key role 
in the education of students from different cultures. To resolve the ability of pupils to manually record knowledge, schools have to establish good teaching and learning methods. The findings of the International Student Evaluation Program (PISA, 2012) were from the Far East, which included the top five nations. Is it a wonder that these countries teach handwriting routinely up to 16 years old? Whatever one interprets, in contrast, Britain is lagging behind. The UK is currently 23rd in Reading, 26th in Mathematics and 20th in Science (out of 68 countries). These current statistics will influence educators even if they compile a new report for 2020 to take any changes into account. The paper ends with suggestions on how and why handwriting can be a priority in the literacy lesson of schools. Some researchers agree that handwriting involves the orchestration of a range of cognitive resources.

The secondary students were taught strategy in one study ("De La Paz \& Graham, 2002") that would allow them to perform various handwriting tasks. They also taught knowledge and skills through a clearly designed programme to execute these tasks. One month after the directions, the pupils were checked. Students in the experimental group carried out long essays, used more mature vocabulary and were more qualitatively capable of communicating and sequencing concepts than other persons in the control group. Also if students have a good depth, they can perform better and require minimum differentiated tasks/results (Stegmann, 2004). It helps pupils to become self-employed by learning about the structure, type and pattern of words. Medway and Wray (2008) argue that capacity (data storage capability) and automaticity are related (to retrieve information onto the page). It was also discovered in a 2012 Saperstein Associates study.

Finally, it was concluded that both components (capacity and automatism) enhance students' ability to communicate and thus increase the quality of their ideas. Improving the handwriting of students therefore has some impact on their ability to enhance the standard of ideas. Another research in the field of neuroscience (Longcamp et al. 2008) has found the potential of students to take various typology variants by studying a new language that is graphically differentiated from English (as written Chinese, Japanese or Hindi). It also helps to memorize and identify different word patterns: more handwriting and regular letter recognition was found in several geographical areas known to include performance and imaging tasks, in particular in the left broca region and in bilateral parietal lobules. These findings together make a clear statement that the fundamental movements remembered during writing are part of the visual recognition of graphic types and letters (Longcamp et al., 2008, p.802). The same research (Longcamp et al, 2008) invited participants to differentiate between mirror images and a group of distinct characters. They did this after using pen and paper and a computer keyboard. The results were that handwriting respondents correctly and permanently recalled the proper orientation of the characters. It helps to deduce that particular gestures memorized during the writing help to recognize graphic types and patterns visually.

Working on the handwriting of pupils will help them improve their reading skills. Similar findings were reported in further studies in which psychologists found a clear link between sequential finger movement and brain function, including experiments at the University of Washington (Saperstein Associates, 2012) (Berninger, 1994) found that: direct handwriting guidance with visual indicators and verbal media leads to enhanced automatic handwriting and better reading of words; training of orthographic engines has improved the 
performance of a task of graphic engine planning for sequential finger movements related to finger composition (Berninger, 1994, p.3). Although the study indicates that reading per se has no added benefit, such evidence suggests a link between writing by hand and increasing accuracy in pupil orientation and word formation. At the very least, their absence did not increase the automaticity of students or increase their ability to register and memorize a variety of spelling variants and word form. In this relationship, a significant argument that needs to be strengthened: the hand recording of textual knowledge (a kinesthetic tool) instead of tapping on a keyboard leads to the long-term development of memory.

The sensation, the structure and the movement of words on paper etc. indicate a connection between memory, ability and coordination of the movement of man, which uses kinesthetic methods (Saperstein Associates, 2012). This is definitely the opinion of some scientists and critics in this area (Berninger, 1994). They conclude that improving handwriting would only further increase the performance and achievement of textual science and humanities pupils (such as Religious Education, History, and Geography).

\subsection{HANDWRITING}

It has been stated that Finland is giving up teaching of handwriting and keyboarding, whereas more than $75 \%$ of schools in the US are no longer giving priority to writing in their literacy lessons (Russell, 2015). True writing (with pencil/pencil) is an anachronistic practice in these countries that is incongruously modern. Social media and their expectations have in several ways overcome conventional skills that pupils learn in school. In literacy education, also in the UK handwriting is no longer a priority as it was 20-30 years ago (Hallows,
2009). This is to a certain degree demonstrated by references to recent legislation such as the English National Curriculum, the Qualification and Curriculum Authority (the quality management body for exams and tests in the UK) as well as the associated structure and guidelines for schools set by the government. For example, the Early Writing Learning Program (by DfEE, 2001) encourages teachers to teach basic teaching skills to people aged 4-7.

Nevertheless it serves as a mere guideline as a directive, though teachers are not required to follow it. Even on Main Stage 2, this is evident. Although there are one or two guidelines for the wording, orientation, size and clarity of letters, there is little information about the cursive styles, motion and speed. Currently, handwriting is not checked or calculated with consistent criteria. With regard to the Level 4 criterion, as Medway and Wray (2008) remember, as long as the applicant scripts are fluent, combined and readable, no other requirement is made of pupils. When pupils reach secondary school, they are assumed to know how to write. Therefore no further instruction is provided to improve upon the skills.. This view is also reflected in the various instruments and corresponding handwriting techniques of primary school. However at the secondary level, those instruments, instructions and facilities are almost entirely absent. However, all other skills are also taught and tested, such as spelling, grammar, vocabulary, reading comprehension, and syntax. This statement that students no longer need handwriting lessons is incorrect. Around 100,000 out of more than 650,000 students have had low English/literacy skills.

Employers and other educational institutions are increasingly desperate at the level of pupils' literacy skills. Statistically, the reading skills of the British pupils lie behind the globe. According to the results of the PISA (PISA, 2012), the United 
Kingdom ranks 20th out of 68 league table nations, while the Far East countries like Japan, Hong Kong, Singapore and Taiwan are top 4 . These are the countries referred to in the Education Act of 2011 by the former Minister of Education of the United Kingdom, Michael Government. Some collaborations have been established between these countries, which emphasize traditional teaching skills and our own teaching and learning strategies. Many countries in the Far East (China, Japan, Taiwan, Singapore, etc.) depend, for example, on handwriting as a key field in providing students with structured minds, cognitive skills and textual knowledge capabilities.

Handwriting is the core of the education and the school curriculum in these countries. Moreover, there is evidence that handwriting contributes to better orthography. While this must be treated with caution (Barnett et al., 2006), the hand movements associated with lettering help the pupils in language relate and develop the concept of a word are unquestionable. This is because kinesthetic learning influences the cognition of pupils. The close relation between the apparent tracing of hand movements and clear and fluid handwriting, for instance, has been seen. (Jones \& Christensen, 2009). Some studies claim that good learning depends on the level of handwriting instructions that pupils obtain and acquire during primary school.

The new exemption from handwriting in secondary schools is also unadvised, as students are essentially denied the tool for continuing education. This will affect their mindset and achievement and in turn, will impact employability and social mobility. For example, a study (Every Child: A Chance Trust, 2009) found that more than half of boys with weak literacy at 16 years believed that school was a waste of time. The results of low educational achievement mean lack of opportunities for the pupils' career prospects and social mobility are clear. If pupils think secondary education is useless, what is the potential for teachers to help them learn knowledge and skills for the labour market?

The economic consequences, however, are just as significant: as a result, the cumulative cost to public funds arising from failure to learn basic literacy skills in primary school years is calculated at $£ 5000$ to $£ 43,000$ per child per 37 year per person per person per 37 year, and between $£ 5,000$ and $£ 64,000$ over a lifetime. This amounts to an annual total of $£ 198$ to $£ 2.5$ billion (Every Child: A Chance Trust, 2009:15). In addition to the real costs, the more time it takes for students to write (without instructions), the harder it is for them to readjust in later school years (Christensen \& Jones, 2005). In other words in order to be easy, demonstrate, speed and readable when they take on the wrong habits/techniques, it becomes harder to correct students' handwriting style. The creativity of students exceeds the quality of the instruments they show in expressing their imagination in this school of thought: as Medwell and Wray point out, children were encouraged to openly compose, use their language and writing skills that are improving but incomplete to express themselves with pencils (Medwell \& Wray, 2008, p. 37). Similarly, the head teacher notes that the shape of the oval, loop and slant of a child these days is less important than what they write.

Letter forming tends to be taught in early school, but handwriting is less important for older children (Mark Brown, Head of St Mary's Catholic Elementary School in Axminster, cited in Hallows, 2009). In reality, the power, the purity and the consistency of the letters of the pupils have been almost relegated to the side lines. However the submission of the responses of pupils in written exams is dependent on the grade received. Furthermore on computers, the preparation, drafting, 
review and proofreading of a work and the feedback on the method it is conceived (evaluated features at A 'Level English) is carried out entirely. As such, they have noted the value of pupil presentation consistency. However, it may be argued that student drafting work by hand will lead to a more rigorous study of language. In addition, secondary students can read, understand and use dense textual knowledge for exams. Teachers also argue that the use of IT in English and literacy computers in particular has made students become inextricably involved, connected and linked to the written text (Doug, 2016 b).

Students are less likely to perform written tasks because teachers rely on a typed job sometimes. This is partly because the improvement of the skills of pupils in IT has been developed as a key area for reform. It is part of career skills and can be adopted by all teachers by offering adequate learning tools and opportunities for learners to use classroom technology. It has also been shown that orthographic-motor integration is closely related to the ability of students to produce creative and wellstructured written text (Christensen, 2005; Roaf, 2001).

This has to do with the cognitive pressure that happens on paper when students write.

The lack of automation in the integration of spelling engines means that learners do not have adequate cognitive capability to accomplish the most challenging aspects of text-making, such as ideation, text-monitoring and pragmatic awareness. A systematic handwriting program has been argued to greatly increase the accuracy of the written text of students facing orthographic-motor integration problems (Christensen, 2004). This may also have a significant effect on the ability of the pupils to spell. For example, a key feature of spelling is established, which means that there is a connection not only to the accuracy of sound and spelling (grapho- phonemic regularity), but also to the likelihood of letters occurring together.

The study establishes a significant link between visual and kinetic orthodoxy learning. It concluded that writing speed is an important part of orthography enhancement. In other words, visual regularity and synchronization in writing of any type are prevalent. However when our pupils teach spelling or handwriting skills, this aspect is rarely put into the equation. Another research (Christensen, 2004) in the USA analyzed the efficacy of a manuscript interventionist project intended to remediate issues of older students in the incorporation of orthographic engines. The curriculum discussed ways to develop the written language skills of students. Two classes of students from the 8th and 9th grade 13 and 14 years respectively) had handwriting practices or had to complete regular written journal entries. There was no difference between the two groups during the pre-test.

The handwriting group, however, showed significantly higher ratings for orthographic engine integration and text length and accuracy in the post test. It led the researchers to conclude that successful intervention could alleviate some of the problems associated with the low achievement of pupils in writing tests and examinations in the form of systemic interventions. Some researchers agree that handwriting is a daunting task that needs a range of cognitive resources to be coordinated. The secondary students were taught strategy in one study (De La Paz \& Graham, 2002) that would allow them to perform various handwriting tasks. They also taught the knowledge and skills to accomplish these tasks through a specifically structured curriculum. One month after the directions, the pupils were checked.

Students in the experimental group produced essays that were lengthy, used more mature 
vocabulary and were qualitatively better at expressing concepts and sequencing them compared to other individuals in the control group. It is also the case that if students have a high capacity depth, they perform better and need minimum differentiated tasks/results (Pickering, Knight, \& Stegmann, 2004). It encourages students to become independent workers in gaining information about the structure, shape and pattern of words. Medway and Wray (2008) suggest that there is a connection between capacity (data storage capability) and automation (to retrieve information onto the page). It is also found in a 2012 study by Saperstein Associates. Finally, the conclusion was that both components (capacity and automation) enhance the ability of students to communicate and thus increase the quality of their ideas. Thus, improving student handwriting has some influence on their ability to download and upload brain data.

Another neuroscience research (Longcamp et al., 2008) found that learning a new language that is graphically distinct from English (as written in Chinese, Japanese or Hindi) improves students' ability to absorb various typology variants. It also helps to memorize and identify different word patterns: more handwriting and regular letter recognition was found in several geographical areas known to include performance and imaging tasks, in particular in the left Broca region and in bilateral parietal lobules. Taken together these findings provide clear arguments for the view of engaging in the visual identification of graphic types and letters by particular gestures while learning to write. Interviewees were asked in the same study to distinguish between a new group of characters and a mirror image. After using pen and paper, and a computer keyboard, they did this. The results were that respondents correctly and indefinitely recalled the right orientation of the characters when handwriting. This helps to deduce that particular gestures memorized during the writing help to recognize graphic types and patterns visually. Working on the handwriting of pupils will help them improve their reading skills. Similar results were documented through further studies in which psychologists found a strong correlation between sequential finger movement and brain activity (Saperstein Associates, 2012), including study at the University of Washington (Berninger, 2006).

The direct handwriting instruction with visual indications and verbal media has been found to develop handwriting automatically and better word reading; orthographic-engine preparation has improved the performance of a graphic-engine planning task for sequential finger movements related to the composition of finger (Berninger, 2006, p.3). Although the study indicates that reading per se has no added benefit, such evidence suggests a link between writing by hand and increasing accuracy in pupil orientation and word formation. Therefore, it might be argued that our side-lining of handwriting skills in recent decades may have helped pupils to achieve less. At the very least, their absence did not increase the automaticity of students or increase their ability to register and memorize a variety of spelling variants and word form. In this connection, a significant argument that needs to be strengthened: the hand recording of textual knowledge (a kinesthetic tool) instead of tapping on a keyboard leads to the long-term development of memory. The sensation, the structure and the movement of words on paper etc. indicate a connection between memory, ability and coordination of the movement of man, which uses kinesthetic methods (Saperstein Associates, 2012).

\section{Conclusion}

This paper accentuates the underperformance of students in this regard (DfEE, 2012; 
PISA report, 2012). It can be suggested that there is a lack of opportunity for schools and educators to raise the level of student achievement. Their new handwriting side-lining as an unacceptable method of learning, particularly in high school, denies our students the opportunity for written and external assessments. They should concentrate on handwriting as a pillar of school education and pedagogical practices if teachers, our government and politicians want to develop literacy skills. This emphasis on handwriting may also contribute to the willingness of politicians to follow the model set by some Far East countries, which invest a relatively large proportion of their literacy not only in primary school, but also in secondary school.

This paper also supports a system to make sure that any student with bad handwriting entering high school can quickly get up to speed. Teachers need to consider implementing efficient, whole school handwriting policies for this reason. A special framework with a collection of specific specifications, realizing the importance of engine coordination, capabilities and speed, will assist these. These policies will also address the needs of students with orthographic motor control disorders, in addition to targeted functional illiteracy (DfEE, 2012). Roaf (2001) also claimed that it must be a key priority for secondary schools to develop a handwriting policy. Teachers themselves should have advanced ideas in their teaching. We should research and develop our output constantly. The central and challenging point is how vocabulary is processed and memorized in vocabulary teaching. If we make deliberate use of the latest achievements in cognitive sciences to enhance methods of teaching vocabulary, we will help students significantly improve the memory impact of English.

The method of teaching vocabulary can also be used to teach text. First the superficial material of the text, such as paragraphs and the specifics of the document, must be understood. Then deep knowledge must be learned. Cognitive psychology theory has a strong theoretical function to direct teachers in their teaching practice. Teachers should know this so that English lessons can be more successful and the learning skills of students can be used to promote their learning. People understand the special laws of the foreign language learning process in a wide variety of ways and from different levels and pay more and more attention to the subjective initiative and imagination of foreign language learners. The teaching of foreign languages under cognitive learning theory allows teachers to research in foreign language learning the internal psychological mechanism of their students which is conducive to innovative thinking and an informed autonomy of learning topics.

Recommendations

This paper synthesized established research on handwriting abilities to allow pupils to perform well in planned activities, such as examinations. It means that students will enhance their performance by teaching, encouraging and requiring their students to practice and exercise their craftsmanship in high school by their previous year. The paper has also described studies that show the link between students' ability to integrate the role of motor and brain. These studies also show that when students write, they have a stronger relationship than when they type with the types and patterns of words. Likewise, schools need to focus on revision approaches by emphasizing handwriting. There is evidence that handwriting helps to remember. The students' ability to record and acquire acquired knowledge is much more perceptible through writing. School students also verify the facts by memory and recording. It is the easiest and most open way to consume textual material. Very few students look for the keyboard by typing; 
- In connection with the writing process, students can imagine and shop letter sequence (spelling). It also helps to automatically render their sentences, without worrying too much about letters, cursive forms, and curvatures. To produce letters by hand, students also have to think in order to examine, evaluate and synthesize textual contents. This can have a positive effect on the success of students in regulated and graduated activities, such as checking whether pace, reading ability and correct word and letter formulation ultimately enable students to accomplish well.;

- Students can build self-esteem through handwriting. This applies to the recent Every Child Matters (2003 Green Paper) and the Recommendations for the ensuing government and policymakers. Handwriting does not only develop the skills but also entrusts students to be more openminded through inclusive approaches and trust of the students in subjects (Yates et al., 1994).

-While training offerors focus on literacy, potential teachers are not encouraged to emphasize handwriting education using successful approaches with consistent frameworks and requirements (Roaf, 2001). There is almost no standardized writing curriculum but the standard program for key stages 1 and 2 of literacy. Teachers need to assist trainees in creating handwriting systems in the classroom. This needs to be done strategically and regularly during the training of teachers;

- Systematic handwriting and daily practice must be developed. Progress is important in the understanding of the handwriting regulatory processes and in the emphasis on pupils with difficulty in coordination. Competences like pen keeping speed and cursive writing should not be rejected as incoherence (Bashore, 1982). They are an important component of primary and secondary education. Potential teachers should emphasize this, and further research is needed into teaching and learning handwriting skills

- Currently, literacy researchers focus more on 'learning to write' at the level of primary school. However studies taking into consideration secondary education is still minimal. This paper suggests a more thorough study of secondary school students' writing habits in order to determine a link between handwriting consistency, their interaction with their subjects and their success in examinations.

\section{References}

1. Berninger, V. (2010). Development of language by hand and its connections to language by ear, mouth, and eye. Topics of Language Disorders, 20, 65-84.

2. Bishop, D. V. M., \& Snowling, M. J. (2011). Developmental dyslexia and specific language impairment: Same or different? Psychological Bulletin, 130, 858-886.

3. Brown, H. D. (2007). Teaching by principles: An interactive approach to language pedagogy (3rd ed.). White Plains, US: Pearson Education.

4. Ferris, D. R. (2010). Second language writing research and written corrective feedback in SLA: Intersections and practical applications. Studies in Second Language Acquisition, 32(2), 181-201. http://doi.org/10.1017/S0272263109990490.

5. Rahimi, M. (2015). The role of individual differences in learners' retention of written corrective feedback. Journal of Response to Writing, 1(1), 19-48.

6. Amrhein, H. R., \& Nassaji, H. (2010). Written corrective feedback: What do students and teachers prefer and why? Canadian Journal of Applied Linguistics, 13, 95-127.

7. Rowe, D. A. (2008). Development of 5469 
writing abilities in childhood. In $\mathrm{C}$. Bazerman (Ed.), Handbook of writing research: History, society, school, individual, text (pp. 401-420). New York: Lawrence Erlbaum Associates.

8. McCutchen, D., Teske, P., \& Bankston, C. (2008). Writing and cognition: Implications of the cognitive architecture for learning to write and writing to learn. In C. Bazerman (Ed.), Handbook of writing research (pp. 451-470). Hillsdale, NJ: Lawrence Erlbaum.

9. Sippett, A. (2015). Counting the cost of poor literacy and numeracy skills, Retrieved from https://fullfact.org/economy/countingcost-poor-literacy-and-numeracy-skills.

10. Shepherd, J. (2010). Poor literacy and maths skills leave teenagers ill-equipped, Retrieved from: http://www. theguardian.com/education/2010/may/07/po or-literacy-numeracy.

11. Morgan, N. (2016). Speech at the NAHT annual conference 2016, Retrieved form: https://www.gov.uk/government/ speeches/nicky-morgan-speech-at-the-nahtannual-conference-2016.

12. Feder, P.K. \& Majnemer, A. (2007). Handwriting development, competency, and intervention, Developmental Medicine \& Child Neurology, 49(4), 312-317.

13. Graham, S. \& Perin, D. (2007). A metaanalysis of writing instruction for adolescent students, Journal of Educational Psychology, 99(3), 445-476.

14. Medwell, J. \& Wray, D. (2008). Handwriting: AForgotten Language Skill?, Language and Education, 22(1), 34-47

15. Cripps, C. \& Cox, R. (2008). Joining the ABC: How and Why Handwriting and Spelling should be Taught Together, Cambridge: LDA Publications
16. Peverley, S. (2006). The importance of handwriting speed in adult writing, Developmental Neuropsychology, 29, 197216.

17. PISA (2012). PISA 2012 Results in Focus: What 15-yearolds know and what they can do with what they know, Retrieved form https://www.oecd.org/pisa/keyfindings/ pisa-2012-results-overview.pdf

18. De La Paz, S. \& Graham, S. (2002). Explicitly teaching strategies, skills, and knowledge: Writing instruction in middle school classrooms, Journal of Educational Psychology, 94(4), 687-698.

19. Gathercole, S.E., Pickering, S.J., Knight, C., \& Stegmann, Z. (2004). Working memory skills and educational attainment: Evidence from National Curriculum assessments at 7 and 14 years of age, Applied Cognitive Psychology, 18, 1-16.

20. Longcamp, M., Boucard, C., Gilhodes, J., Anton, J., Roth, M., Nazarian, B. \& Velay, J. (2008). Learning through Hand- or Typewriting Influences Visual Recognition of New Graphic Shapes: Behavioural and Functional Imaging Evidence, Journal of Cognitive Neuroscience, 20(5), 802-815.

21. Yates, C., Berninger, V., \& Abbott, R. (1994). Writing problems in intellectually gifted children, Journal for the Education of the Gifted, 18, 131-155.

22. Saperstein Associates (2012). 'Handwriting in the 21st Century? Research Shows Why Handwriting Belongs in Today's Classroom: A Summary of Research Presented at Handwriting in the 21st Century? An Educational Summit', Saperstein Associates, http://act.zaner-bloser.com/ v2/files/H2948_HW21Summit_white_paper .pdf, 2-7. 
23. Russell, H. (2015). Signing off: Finnish schools phase out handwriting classes, Retrieved from: http://www. theguardian.com/world/2015/jul/31/finnishschoolsphase-out-handwriting-classeskeyboard-skills-finland.

24. Hallows, N. (2009). The slow death of handwriting, Retrieved form http://news.bbc.co.uk/1/hi/7907888.stm.

25. PISA (2012). PISA 2012 Results in Focus: What 15-yearolds know and what they can do with what they know, Retrieved form https://www.oecd.org/pisa/keyfindings/ pisa-2012-results-overview.pdf.

26. Jones, D. \& Christensen, C. (2009). The relationship between automaticity in handwriting and students' ability to generate written text, Journal of Educational Psychology, 91, 44-49.

27. Every Child: a Chance Trust (2009). The long term costs of literacy difficulties, Retrieved from http:// readingrecovery.org/images/pdfs/Reading Recovery/Research_and_Evaluation/long_t erm_costs_of_literacy_difficulties_2nd_edit ion_2009.pdf, 1-52

28. Medwell, J. \& Wray, D. (2008). Handwriting: AForgotten Language Skill?, Language and Education, 22(1), 34-47

29. Doug, R. (2016a). If we deny pupils handwriting, we are robbing them of a form that individualises them, Retrieved from https://www.tes.com/news/school-news/ breaking-views/if-we-deny-pupilshandwriting-we-arerobbing-them-a-form (last accessed 14/6/16)

30. Doug, R. (2016 b). Narrative Study: An Immigrant Pupil's Experience of English in Multicultural Education, (Doctoral dissertation), University of Birmingham.
31. Jones, D. \& Christensen, C. (2005). The relationship between automaticity in handwriting and students' ability to generate written text, Journal of Educational Psychology, 91, 44-49.

32. Gathercole, S.E., Pickering, S.J., Knight, C., \& Stegmann, Z. (2004). Working memory skills and educational attainment: Evidence from National Curriculum assessments at 7 and 14 years of age, Applied Cognitive Psychology, 18, 1-16.

33. Longcamp, M., Boucard, C., Gilhodes, J., Anton, J., Roth, M., Nazarian, B. \& Velay, J. (2008). Learning through Hand- or Typewriting Influences Visual Recognition of New Graphic Shapes: Behavioural and Functional Imaging Evidence, Journal of Cognitive Neuroscience, 20(5), 802-815.

34. Saperstein Associates (2012). 'Handwriting in the 21st Century? Research Shows Why Handwriting Belongs in Today's Classroom: A Summary of Research Presented at Handwriting in the 21st Century? An Educational Summit', Saperstein Associates, http://act.zaner-bloser.com/ v2/files/H2948_HW21Summit_white_paper .pdf, 2-7

35. Roaf, C. (2001). Handwriting, Achievement and School Policy, National Foundation for Educational Research, Issue 25, https://www.nfer.ac.uk/nfer/PRE_PDF_ Files/01_25_07.pdf

36. Roaf, C. (2001). Handwriting, Achievement and School Policy, National Foundation for Educational Research, Issue 25, https://www.nfer.ac.uk/nfer/PRE_PDF_ Files/01_25_07.pdf

37. Bashore, T. (1982). Is handwriting posture associated with differences in motor control? An analysis of asymmetrics in the readiness 
potential, Neuropsychologia, 20(3), 99-111. 